\title{
Exclusión de la prueba pericial científica (de baja calidad epistémica) en fase de admisibilidad en procesos penales de tradición románica- continental: Diálogo entre dos culturas jurídicas
}

\begin{abstract}
Exclusion of the scientific expert evidence (low epistemic quality) in the admissibility in criminal proceedings of civil law tradition: Dialogue between two legal cultures
\end{abstract}

\author{
Juan Sebastián Vera Sánchez ${ }^{1}$ \\ Universidad de Chile, Santiago, Chile \\ jsvera@derecho.uchile.cl \\ https://orcid.org/0000-0001-9578-8213
}

\begin{abstract}
Resumen: En este trabajo analizamos los criterios de exclusión de la prueba pericial científica de baja fiabilidad epistémica proveniente de dos culturas jurídicas diversas: common law y civil law. Se desarrolla la relación entre ambos grupos de criterios para afirmar que los criterios Daubert pueden ser aplicables en los sistemas de enjuiciamiento del civil law cuando se trate de casos claros. La libertad de incorporación de medios de prueba, el derecho a la prueba y el debido proceso son limitaciones que impiden una aplicación amplia de la exclusión probatoria en estos casos.
\end{abstract}

Palabras Clave: Fallo Daubert; prueba pericial; reglas de exclusión.

ABSTRACT: In this paper we analyze the exclusion criteria of scientific expert evidence of low epistemic reliability from two different legal cultures: common

1 Doctor en Derecho Universidad de Barcelona. Profesor Asistente de Derecho procesal, Universidad de Chile. Dirección postal: Av. Santa María 076, Providencia, Chile. Correo electrónico: juansverasanchez@gmail.com. Este artículo fue escrito en el contexto de la ejecución del Proyecto FONDECYT de Iniciación $\mathrm{N}^{\mathrm{o}}$ No11180563: "Las condenas fundadas en el testimonio de la víctima en materia penal: ¿epistémicamente posible? ¿jurídicamente aceptable?”. 
law and civil law. We develop the relationship between both groups of criteria to argue that the Daubert criteria may be applicable in civil law when dealing with clear cases. The freedom of proof, the right to evidence and due process are limitations that prevent a broad application of the exclusion of evidence in these cases.

KEYWORDS: Daubert decision; expert evidence; exclusionary rules.

SUMARIO: Introducción; 1. La inquietud que nos deja el fallo Daubert; 2. La exclusión probatoria por falta de fiabilidad epistémica en los ordenamientos del civil law. ¿Cómo ha sido tratada por el derecho procesal continental? 2.1 La prueba pertinente. 2.2. La prueba idónea y útil. 2.3. Relevancia como utilidad, ¿un primer nexo?; 3. La exclusión probatoria y la normatividad de la libertad de incorporación de la prueba; 4. ¿Es posible la recepción del fallo Daubert en los procesos penales románico-continentales?; Conclusiones; Bibliografía.

\section{INTRODUCCIÓN}

La prueba pericial científica cada vez más está presentando importancia en los procesos judiciales ${ }^{2}$. En efecto, desde un punto de vista tradicional, ya Mittermaier señalaba que la intervención de los peritos ha de tener lugar en una causa criminal cuando "se presentan ciertas cuestiones importantes, cuya solución, para poder producir convencimiento en el ánimo del juez, requieren el examen de hombres (sic) provistos de aptitud y de conocimientos facultativos y especiales"3. Por su parte, según Serra, la principal función de los peritos es la de facilitar las máximas de experiencia técnicas especializadas al juez. No se trataría en este sentido, de un medio de prueba más, sino de un medio de corregir la deficiencia técnica, lógica del juzgador ${ }^{4}$.

\footnotetext{
2 Así, Alcoceba (2018), p. 220.

3 Mittermaier (2006), p. 181.

4 Serra (1969), p. 364.
} 
El incremento del uso de expertos en los procesos judiciales es una manifestación del rol que se les atribuye en la sociedad en general ${ }^{5}$. Además, dicho incremento es un síntoma de la importancia que se la ha otorgado a la especialización funcional en nuestra época ${ }^{6}$.

El auge de la cientificidad ha traído consigo la problemática de producción de ciencia de baja calidad epistémica, con los correspondientes efectos perniciosos que pueden generar en los procedimientos judiciales. El más notorio de ello, según dan cuenta estudios, es el efecto persuasivo o "sesgo de cientificidad" o "mito de la infalibilidad"7 que posee la prueba pericial científica, por el solo hecho de serlo, que tiende a elevar la apreciación de su valor epistémico más allá del que realmente puede extraerse a partir del análisis de su metodología y conclusiones. Así, algunos teóricos de la prueba ya comienzan a hablar de una sobrevaloración epistémica y semántica de la prueba pericial científica ${ }^{8}$, especialmente presente en disciplinas científicas complejas ${ }^{9}$. Se deben adoptar medidas de resguardo al interior de los procedimientos judiciales para que la prueba pericial científica no sea valorada de forma indebida? ¿En qué momento procesal?

A partir de los años 2000, los procesos penales iberoamericanos han experimentado una gran cantidad de modificaciones o reformas, incorporando elementos de la justicia penal de los Estados Unidos y Reino Unido $^{10}$, en combinación con instituciones históricas de la tradición románica-continental. El objeto era aproximar la justicia penal a los modelos de procesos acusatorios puros, so pretexto de una mayor rapidez y publicidad de los enjuiciamientos penales, con todo lo que ello puede significar para los poderes probatorios de las partes y del juez $^{11} \mathrm{y}$, en definitiva, para la calidad de la decisión jurisdiccional. Una de esas manifestaciones ha sido atribuir a la fase intermedia de los

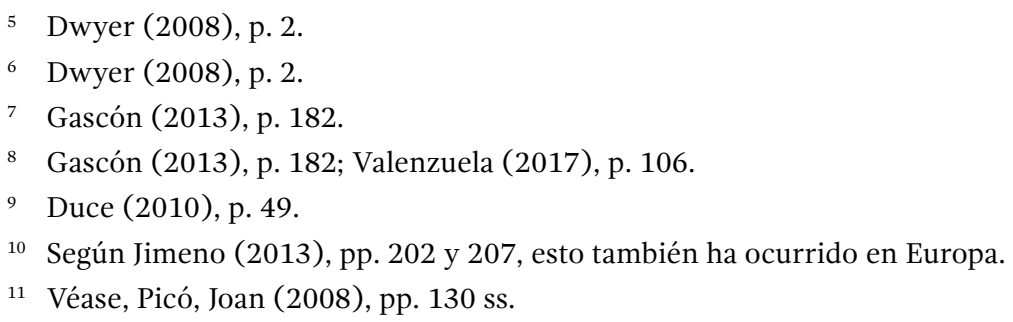


procesos penales el momento procesal idóneo para discutir acerca de la admisibilidad de la prueba, a través de la aplicación de reglas de exclusión basadas en fundamentos epistémicos y extraepistémicos ${ }^{12}$. Se trataría, entonces, de un momento procesal de selección de prueba o de depuración del acervo probatorio abstracto ${ }^{13}$, de forma que solo sean rendidos e incorporados en el juicio oral los medios de prueba epistémicamente relevantes y que no hayan sido obtenidos con infracción a los derechos fundamentales.

La cuestión de la exclusión de la prueba pericial científica de baja calidad epistémica no ha sido tratada con suficiente atención por el Derecho procesal continental. Entre otras razones, porque la relevancia de la cuestión se manifiesta a partir de la segunda mitad del siglo XX, con el "boom" del conocimiento científico aplicado a los procesos judiciales.

En el ámbito anglosajón, la cuestión se ha debatido intensamente luego de la decisión Daubert v. Merrel Dow Pharmaceuticals de la Corte Suprema de los Estados Unidos ${ }^{14}$. Dicho fallo se refiere a los criterios de cientificidad de la prueba pericial, que permitan su exclusión en la fase de admisibilidad a la manera de un filtro de calidad epistémica de la prueba. Lejos de considerar la decisión Daubert el fruto de una discusión interna, algunos autores destacan que los problemas enfrentados en la sentencia son extremadamente importantes en todos los sistemas procesales ${ }^{15}$, más allá de una determinada y precisa cultura jurídica. La cuestión se vuelve más compleja cuando se ahonda en los fundamentos y justificaciones de la existencia de dichas normas probatorias en uno u otro sistema, y la extensión de sus alcances, por notorias diferencias entre ambos tipos de culturas.

12 Cuando hablamos de fundamentos epistémicos, estos solo dicen relación con facilitar la búsqueda de la verdad en cuanto finalidad de la etapa probatoria. Por su parte, los fundamento extrapistémicos buscan cautelar otros intereses de importancia para la decisión justa, más allá de la mera averiguación de lo sucedido.

13 Así, Vera (2017), p. 158.

14 Supreme Court, Daubert v. Merrel Dow Pharmaceuticals (92-102), 509 U.S. (1993), june 28, 1993. Una crítica germinal respecto de las cuestiones epistémicas del fallo pueden verse en Vera (2018), pp. 43 y ss.

15 Taruffo (2008), p. 99. 
¿Es posible aplicar el criterio de la cientificidad para admitir/ excluir la prueba pericial en el contexto de los procesos penales románico-continentales?

La finalidad de este trabajo es reflexionar acerca de si es posible hacer una traslación del cuestionamiento de la exclusión de la prueba pericial por baja calidad epistémica en sede de admisibilidad -como se ha puesto de manifiesto en el "evidence" anglosajón a través de fallo Daubert- a procesos penales de ordenamientos jurídicos románicoscontinentales, sobre la base de iguales justificaciones y fundamentos. Lo anterior, poniendo atención en si dicha problemática ha sido o no conocida por nuestro derecho procesal y, acto seguido - de ser así- valorando la posibilidad de existencia de ciertos rasgos comunes en la materia entre ambas tradiciones jurídicas. De esta forma, se intentará dar cuenta acerca de la posibilidad de construir un diálogo entre ambas culturas normativas, a través de la vinculación que puede existir entre el término fiabilidad epistémica de la cultura anglosajona y el de utilidad de la prueba del derecho procesal continental.

\section{La inquietud que nos deja el fallo Daubert}

En Estados Unidos, a partir de los años 1960, la prueba pericial deja su lugar residual para empezar a tomar una mayor relevancia. Ello, entre otras razones, por el gran poder de convicción que presenta la pericia científica para dar por acreditado los hechos ${ }^{16}$, especialmente cuando dicha prueba se rinde frente a un jurado.

Los padres de los menores Jason Daubert y Eric Schuller, en 1984, entablaron una demanda civil por daños en contra de Merrel Dow Pharmaceuticals Inc., ante la Corte del Estado de California, alegando que la causa de las malformaciones congénitas de sus hijos había sido la ingesta materna -durante la gestación-del medicamento "Bendectin", cuya patente pertenecía a dicha farmacéutica.

La demandada alegó que dicho fármaco no era teratogénico, por lo que no podría ser la causa de las malformaciones. Para ello presentó la

16 Bachmaier (2009), p. 119. 
declaración de un médico especialista en Epidemiología con una amplia acreditación en relación con los daños producidos por la exposición a sustancias químicas y biológicas. En efecto, dicho especialista afirmó que no existían estudios publicados que demostraran una correlación estadística significativa entre la ingesta del medicamento y las malformaciones de los menores. A su turno, los demandantes presentaron testimonios de sus propios expertos que afirmaban que dicho medicamento podría posiblemente causar daños congénitos.

La corte del distrito decidió que el testimonio experto presentado por los actores no era concluyente precisamente, porque se afirmaba que el fármaco "posiblemente" había causado las malformaciones, declarando que el criterio jurídico adecuado para admitir o excluir una prueba científica era la "aceptación general" del área relevante de los principios subyacentes, en consonancia con el estándar Frye ${ }^{17}$.

En este sentido, se estimó que los estudios epidemiológicos previos presentados por los demandantes debían ser inadmitidos, porque no habían sido publicados o sujetos a una evaluación por pares.

Los demandantes apelaron respecto de esta decisión que, a su turno, fue confirmada por la Corte de Apelaciones del noveno circuito estadounidense, asumiendo "la aceptación general de la comunidad científica de referencia” como el estándar de admisión de las pruebas periciales.

Finalmente, el caso llegó a la Corte Suprema de los Estados Unidos en el año 1993. Los demandantes argumentaron que las Reglas Federales de Evidencia (en adelante FRE) habían superado el criterio o estándar Frye, de momento que la valoración de este tipo de prueba correspondía exclusivamente al jurado y no a los jueces que deciden sobre la admisibilidad de prueba. En el otro extremo, los demandados afirmaron que los jueces tenían la responsabilidad de asegurarse que todas las pruebas admitidas fuesen relevantes y fiables.

La Corte Suprema de los Estados Unidos resolvió por unanimidad la cuestión jurídica central del caso, declarando que no era exacto interpretar las regulaciones de la FRE a la luz del estándar Frye. En efecto, según la corte, el texto normativo no hacía referencia explícita ni implícita a la

17 Al respecto, véase, Gardner/Anderson (2013), p. 483. 
"aceptación general del área de conocimiento" como criterio de admisión. Sin embargo, los jueces para valorar la admisibilidad debían entender el texto de las FRE, de acuerdo con el criterio de la fiabilidad probatoria, tomando como referencia la validez científica del método utilizado por el experto. Acto seguido, la Corte Suprema procedió a indicar a manera de recomendación o sugerencia una serie de factores para valorar la cientificidad de la prueba. De esta forma, sin ser exhaustivo, se indicaron los siguientes cuatro factores o criterios: "a) si la teoría o técnica puede ser o ha sido sometida a prueba, lo que constituiría un criterio que comúnmente distinguiría a la ciencia de otro tipo de actividades humanas; b) si la teoría o técnica empleada ha sido publicada o sujeta a la revisión por pares; c) el rango de error conocido o posible, si se trata de una técnica científica, así como la existencia de estándares de calidad y su cumplimiento durante su práctica; y, Finalmente, d) si la teoría o técnica cuenta con una amplia aceptación de la comunidad científica relevante"18.

El Fallo Daubert pone de manifiesto la conveniencia de evitar los efectos perjudiciales de que una prueba pericial de baja calidad epistémica pueda ser rendida en juicio, no solo dificultando la búsqueda de la verdad, sino también pudiendo generar sesgos en relación con su valoración. Se propone, de esta forma, excluir la prueba pericial que adolezca de fiabilidad, y que pueda generar una falsa impresión de la realidad como ha sucedido, por ejemplo, con la prueba del polígrafo. En efecto, de todas las decisiones importantes que se suelen citar en los Estados Unidos en la materia, parece ser que el fallo Daubert es el único que establece un estándar de cientificidad de la prueba pericial ${ }^{19}$.

Para Zuckermann y Roberts, es preferible considerar "expert evidence" como un tópico organizado de conocimiento a partir de aspectos de autoridad epistémica, de la trasparencia del proceso inferencial, y de la durabilidad de la confianza social en la legitimidad de los veredictos en lo penal ${ }^{20}$. En este sentido, la decisión Daubert asumiría una noción de perito limitada desde el punto de vista continental: solo circunscrita

18 Un desarrollo más extenso y pormenorizado puede verse en Vázquez (2015), p. 91 ss. También, Bachmaier (2009), pp. 124 y ss; Sánchez (2019), pp. 221 ss.

19 Alcoceba (2018), p. 235.

20 Roberts y Zuckerman (2010), p. 469. 
al experto de ciencias "duras" 21 , aun cuando con posterioridad se ha hecho una aplicación extensiva hacia áreas técnicas ${ }^{22}$ que no deja, por tanto, de ser un poco forzada. Es decir, el experto del caso Daubert solo sería un perito científico y-prima facie- no quedarían incluidos en él los peritos versados en artes u oficios. Aquí hay una diferencia contextual importante que a veces pasa inadvertida: in ovo, los alcances de la decisión Daubert solo afectan a un tipo de prueba pericial denominada científica. Por ello no ha de extrañar que algunos autores continentales denuncien la idoneidad y necesidad de contar con una decisión "Daubert", pero con criterios referidos a las ciencias sociales, culturales y/o humanistas ${ }^{23}$.

\section{LA EXCLUSIÓN PROBATORIA POR FALTA DE FIABILIDAD EPISTÉMICA EN LOS ORDENAMIENTOS DEL CIVIL LAW. ¿CóMO ha SIDO tRatada POR EL DERECHO PROCESAL CONTINENTAL?}

Parece de toda lógica que la "seudo prueba pericial", débil epistémicamente, sea excluida del juicio, como acertadamente muestra la evolución del fallo Daubert. Sin embargo, este tipo de exclusión no es algo propio ni menos originario de la cultura anglosajona. La tradición procesal continental realizaba una labor análoga a partir de las nociones de "pertinencia", "idoneidad", "utilidad" de la prueba, como una forma de protección de la economía procesal en relación con la correcta inversión de los fondos públicos destinados a la administración de justicia $^{24}$. Sin embargo, los ordenamientos jurídicos del civil law, en su mayoría, no contienen una definición legal de lo que es ciencia para

21 Sobre el concepto de "hard sciences” y “soft sciences” véase, Sánchez (2019), pp. 44 ss.

22 Así, en la decisión del 1999 de la Supreme Court In Kumho Tire Co. v. Carmichael (119 S. Ct. 1167 (1999).

23 Taruffo (2008), p. 286.

24 Devis Echandía (1988), p. 133: "Puede decirse que éste (principio de la pertinencia, idoneidad o conducencia y utilidad de la prueba) representa una limitación al principio de la libertad de la prueba, pero es igualmente necesario, pues significa que el tiempo y el trabajo de los funcionarios oficiales y de las partes en esta etapa del proceso no debe perderse en la práctica de medio que por sí mismos o por su contenido no sirvan en absoluto para los fines propuestos y aparezcan claramente improcedentes o inidóneos" 
los efectos de la prueba pericial ${ }^{25}$, cuestión que impide enfrentar la materia -desde el exclusivo plano de un mandato normativo- a partir del dilema de la demarcación ${ }^{26}$.

Ahora, sí conviene advertir que la exclusión probatoria por motivos epistémicos ha sido abordada en la tradición continental desde la perspectiva de una relación entre el medio de prueba y el "thema probandum”,y no necesariamente teniendo como objeto el área disciplinar del cual emana el medio de prueba. Ello, sin duda, dificulta el análisis. Las escasas reglas de exclusión especiales en materia de prueba pericial parecieren apuntar a requisitos subjetivos o de credibilidad del perito (seriedad y profesionalismo, por ejemplo, como se afirma en Chile). Desde esta perspectiva, la idoneidad de la producción epistémica de la ciencia, arte u oficio que profesa el perito es una cuestión que se ha valorado indirectamente en sede continental.

Pues bien, en lo que sigue analizaré brevemente las nociones de pertinencia, idoneidad e utilidad y nos preguntaremos si por medio de sus contenidos es posible invocar la exclusión probatoria por falta de calidad epistémica de la prueba pericial científica.

\subsection{LA PRUEBA PERTINENTE}

La doctrina ha señalado que el vocablo pertinencia expresa una relación entre el medio de prueba y el thema probandum. Según Montero, la pertinencia exige que el hecho que se prueba a través del medio de prueba tenga relación con el objeto del proceso ${ }^{27}$. El concepto de pertinencia, por su parte, presupone el empleo de categorías procesales como objeto del litigio, pretensión, excepción, etc., todos conceptos no conocidos por la tradición anglosajona.

25 Alcoceba (2018), p. 226.

26 Una forma en enfrenta la depuración epistémica de la prueba pericial es asumiendo que sólo la prueba que emane de un área denominada "ciencia" pueda superar los filtros de admisibilidad. Ello nos llevaría a intentar delimitar o trazar una frontera entre lo que es ciencia y lo que no, cuestión que en filosofía de denomina “dilema de la demarcación”. Un mayor detalle al respecto, véase en Vázquez (2015), pp. 87 ss.

27 Montero (2005), p. 151. En igual sentido, Jauchen (2006) p. 24. 
La prueba pertinente se debe referir a los hechos que constituyen la causa de pedir de la pretensión ejercitada por el demandante o a los hechos con que el demandado ha ampliado el objeto del debate ${ }^{28}$. En una versión más depurada, algunos autores indican que la pertinencia exigiría una doble relación de idoneidad, tanto con el thema probandum como con el enunciado fáctico en específico sobre el cual versaría la prueba $^{29}$. En efecto, parte de la doctrina distingue entre pertinencia funcional y material, debiendo ambas ser satisfechas por el medio de prueba respectivo. La pertinencia funcional supone que los medios de prueba sean de realización posible, mientras que el aspecto material de la misma estaría referido a que el resultado de la prueba tenga relación respecto del objeto de la decisión ${ }^{30}$.

En principio, se podría excluir el concepto de pertinencia de la discusión tratada en este trabajo porque, en un sentido bien estricto, la prueba pericial científica de baja calidad epistémica generalmente estará referida al objeto del juicio. Por ejemplo, como cuando se afirma que por medio del polígrafo es posible probar la autoría de un delito por parte del acusado. En este sentido, para mí, la fiabilidad de la prueba científica es una cuestión distinta a las versiones más estrictas de la pertinencia en materia de derecho procesal continental, por ello no daría cabal cobertura a estos casos.

\subsection{LA PRUEBA IDÓNEA Y ÚTIL}

La inutilidad e inidoneidad, como conceptos procesales que permiten una exclusión probatoria, han sido elementos utilizados y conocidos en diversos ordenamientos jurídicos. Por ejemplo, el artículo 283.2 de la Ley 1/2000, 7 de enero "Ley de Enjuiciamiento civil española” (en adelante LEC), señala expresamente que "tampoco deben admitirse, por inútiles, aquellas pruebas que, según reglas y criterios razonables y seguros, en ningún caso puedan contribuir a esclarecer los hechos controvertidos". Según Montero, la inutilidad en sentido estricto puede atender a dos tipos

\footnotetext{
28 Montero (2005), p. 151.

29 Sánchez (2019), p. 205.

30 Montón (1999), p. 198.
} 
de razones. En primer lugar, cuando el medio de prueba es inadecuado respecto del fin que se persigue. En segundo lugar, cuando el medio de prueba es superfluo. Lo primero sucedería cuando el medio probatorio no es adecuado para verificar con él las afirmaciones de hecho que pretenden ser probadas por las partes; lo segundo, "bien porque se han propuesto dos pruebas periciales con el mismo fin, bien porque el medio de prueba ya se había practicado antes". Como el mismo autor advierte, muchas veces se emplean por la jurisprudencia indistintamente las nociones de pertinencia y utilidad como sinónimos ${ }^{31}$, generándose con ello una confusión que no es posible justificar al interior de la doctrina procesal. Por otro lado, como también se puede advertir del desarrollo procesal de este concepto, muchas veces se confunde una cuestión epistémica con una cuestión competencial. Es decir, si la prueba sirve o no para saber la verdad de lo sucedido y la necesidad de su utilización por parte del juez. Para Sánchez, la utilidad estaría vinculada a la idoneidad del medio de prueba para generar información respecto de los enunciados fácticos que se alegan ${ }^{32}$.

Ahora, necesidad y utilidad son términos diversos porque apuntan a perspectivas diferentes. El primero, vincula al juez con el conocimiento aportado; el segundo, el conocimiento aportado con el thema probandum. La necesidad es una cuestión quizá más propia de la problemática que Stein trata en su monografía clásica referida al conocimiento privado del juez ${ }^{33}$. La utilidad, por su parte, parece presentarse de una manera genuinamente epistemológica.

En Alemania, según el §244, III StPO, los requerimientos de prueba pueden ser rechazados bajo cuatro grandes supuestos. Uno de ellos es en caso de inutilidad. Esto es cuando el medio de prueba es completamente inidóneo o es inasequible. El medio de prueba será completamente

31 Montero (2005), p, 156.

32 Sánchez (2019), p. 209.

33 Stein (1990), p. 7. En efecto, la problemática radica en dar importancia en la información que haya obtenido el juez, que sea relevante para decidir la cuestión, cuyo origen se encuentre fuera del juicio o forme parte de su conocimiento privado. En principio, esta posibilidad se rechaza, argumentando que el juez necesita de prueba rendida en el juicio para poder fundar su decisión conforme a ella. Mayores antecedentes de la discusión pueden verse en Vega (1993), pp. 50 ss. 
inidóneo si se puede afirmar con seguridad, con independencia del curso de obtención de prueba, que el resultado no puede derivarse del antecedente probatorio $^{34}$. La completa idoneidad debe apreciarse de forma restrictiva, y muy cautelosa ${ }^{35}$. Entre otras razones, porque implica una anticipación de la valoración probatoria, cuestión que en sí misma es peligrosa y ha sido advertido tanto por la jurisprudencia como por la doctrina ${ }^{36}$. Igualmente, debe ser apreciada en sí misma, con prescindencia de otros medios de prueba, debiendo existir una seguridad en su concurrencia ${ }^{37}$. Para Peters, la completa inidoneidad de un testigo puede basarse en cuestiones físicas (sordera, ceguera), psíquicas (enfermedad mental) o morales (enemistad con el acusado) ${ }^{38}$. Según Göbel, la completa inidoneidad podría estar relacionada con la credibilidad o memoria en el caso de los testigos, pero en circunstancias muy específicas ${ }^{39}$

En cuanto al dictamen de expertos, según Roxin, "un perito no es completamente inidóneo cuando no puede declarar sobre la culpabilidad o inocencia, sino solo sobre la mayor o menor probabilidad de la comisión del hecho o de la afirmación que constituye el objeto de la prueba”. Agrega que de "ninguna manera se puede equiparar el valor probatorio reducido o dudoso a inidoneidad completa del medio de prueba”. En cambio, "tanto un vidente como un dictamen parasicológico son completamente inidóneos como medios de prueba” ${ }^{40}$. Para Sánchez, las prueba basadas en el tarot o en el horóscopo se excluirían por inútiles porque, aunque se trate de pruebas pertinentes, "es por todos sabido que es imposible conocer científicamente unos hechos pasados o futuros mediante métodos adivinatorios”41. En igual sentido se pronuncia Volk en relación con la parasicología ${ }^{42}$.

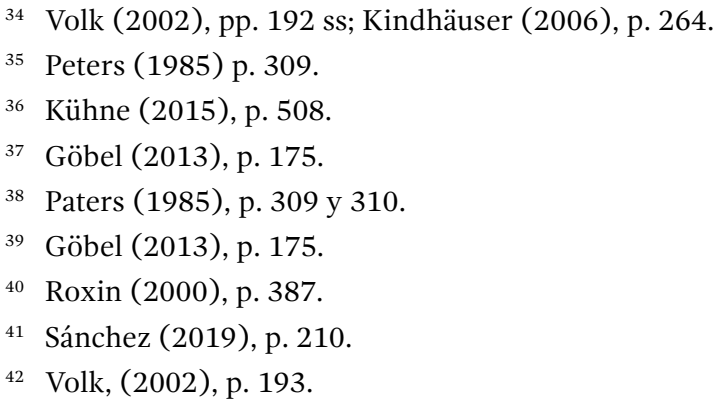


Para Cordero, en Italia, sería prueba inidónea la observación de los pájaros practicada en Roma por los augures, por los oráculos, en sesiones espiritistas o astrológicas o luego en los juicios del féretro ${ }^{43}$.

Como se ve, el cuestionamiento de la exclusión de la prueba pericial por baja calidad epistémica ya era una problemática conocida por los ordenamientos procesales continentales sobre la base de los conceptos de utilidad e idoneidad de la prueba. Aunque claro, sin la completa riqueza que la integración de la Epistemología aporta conceptualmente al "evidence" anglosajón. Pero sí, con la ventaja de una herencia procesal históricamente muy prolongada en el tiempo.

\subsection{RELEVANCIA COMO UTILIDAD, ¿UN PRIMER NEXo?}

Algunos autores han señalado que la prueba es relevante cuando permita fundar sobre los hechos un juicio de probabilidad. La idoneidad de la prueba para generar una posible y/o probable convicción puede ser denominada como relevancia o utilidad de la prueba ${ }^{44}$. En este mismo sentido, la relevancia o utilidad de la prueba está en estrecha relación con la importancia, idoneidad y eficiencia de los antecedentes probatorios para generar un grado de confirmación del enunciado fáctico debatido ${ }^{45}$. La doctrina también ha puesto de manifiesto que la relevancia no puede ser determinada por un solo parámetro, presenta diversas acepciones y solo una de ellas estaría vinculada con cuestiones empíricas ${ }^{46}$. Precisamente esta última es la que permite la exclusión de prueba en los casos en que ella es manifiestamente superabundante o superflua ${ }^{47}$. Binder concibe la exclusión probatoria como el ejercicio de una potestad de policía de los tribunales en los casos de prueba inútil, impertinente, superabundante o ilícita. Por su parte, en la hipótesis de inutilidad, la prueba no contiene

\footnotetext{
43 Cordero (2000), p. 47.

44 Cafferata (1998), p. 22.

45 Jauchen (2006), p. 25.

46 Maier (1996), p. 93. Para el mismo autor, ocurriría en el caso de los hechos notorios y sus significados próximos como cuando se permite excluir la prueba por evidente o manifiestamente superabundante o superflua.

47 Maier (1996), p. 93.
} 
información referida a las hipótesis fácticas debatidas, a diferencia de la prueba impertinente, que contiene información pero esta no está referida al thema probandum ${ }^{48}$.

Por su parte, Taruffo señala que "la relevancia es un estándar lógico de acuerdo con el cual los únicos medios de prueba que deben ser admitidos y tomados en consideración por el juzgador son aquellos que mantienen una conexión lógica con los hechos del litigio, de modo que pueda sustentarse en ellos una conclusión acerca de la verdad de los hechos" ${ }^{49}$. En este sentido, el jurista italiano considera que dicha conexión lógica es cognitivamente instrumental, pues serán medios de prueba relevantes aquellos que puedan ofrecer una base cognitiva para establecer la verdad de un hecho en el litigio, es decir, una información sobre tal hecho que sea superior a cero ${ }^{50}$. Para May, en el Reino Unido, relevancia es un concepto difícil de definir, pero más o menos puede significar que la prueba es relevante si sus efectos pueden hacer más o menos probable la existencia de cualquier hecho que pueda ser vinculado a la inocencia o culpabilidad del acusado ${ }^{51}$.

Ingram, en Estados Unidos, señala que la relevancia es la conexión que existe entre un hecho que se ofrece para ser probado y el asunto que se tiene que probar $^{52}$. Igualmente, Nemeth indica que la prueba relevante debe tener una conexión o nexo lógico entre un valor probatorio inherente y una proposición que busca ser probada ${ }^{53}$. El Model Code of Evidence en su Regla 1 define prueba relevante como aquella prueba que tiene alguna tendencia en razón de probar cualquier asunto material incluyendo opiniones ("opinion evidence") y testimonios de oídas ("hearsay evidence") ${ }^{54}$. La regla 401 de las FRE señala que la prueba es relevante si: a) tiene alguna tendencia para hacer los hechos más o menos probables

\footnotetext{
Binder (1999), p. 258.

9 Taruffo (2008), p. 38.

Ibid, p. 38.

1 May (1999), p. 8.

52 Ingram (2012), p. 46.

53 Nemeth (2001), p. 6.

54 Nemeth (2001), p. 6.
} 
de lo que sería sin la prueba, y b) el hecho es de importancia para la determinación de la acción ${ }^{55}$.

Por último, como advierte Taruffo, el término relevancia es común a los diversos sistemas probatorios ${ }^{56}$. Si bien no se pueden deslindar y separar completamente las nociones de relevancia y de utilidad o idoneidad de la prueba, pareciera ser que los déficits epistémicos de la prueba pericial han de ser circunscritos más propiamente a los segundos. Entre otras razones, por el contenido que presenta el concepto de relevancia, que trasunta la diferencia de culturas jurídicas.

\section{LA EXCLUSIÓN PROBATORIA Y LA NORMATIVIDAD DE LA LIBERTAD DE INCORPORACIÓN DE LA PRUEBA}

La libertad de incorporación de los medios de prueba, - no como principio epistémico propugnado por las corrientes abolicionistas, sino más bien en cautela de intereses extraepistémicos como el derecho a la prueba, el debido proceso ${ }^{57}$, economía procesal, derecho de tutela judicial, etc.,--aconsejan que las limitaciones probatorias y las reglas de exclusión sean limitadas y excepcionales. Quizá en ello radica que no haya sido objeto de discusión en sede de admisibilidad probatoria la exclusión de la prueba pericial de baja calidad epistémica, porque prima facie, ello quedaría dentro del margen de lo tolerable al tratarse de prueba, estricto sensu, relevante y en definitiva ser un tema más propio de la valoración probatoria. También hay que tener presente que el concepto de "regla de exclusión" tiene un marcado origen anglosajón, cuyos procesos penales tienen una fase de admisibilidad probatoria bastante delineada, pero

55 Las FRE dispone "Rule 401 - Test for Relevant Evidence. Evidence is relevant if:(a) it has any tendency to make a fact more or less probable than it would be without the evidence; and, (b) the fact is of consequence in determining the action".

56 Taruffo (2008), p. 40. En relación con el common law, véase, Roberts y Zuckerman (2010), p. 99 ss.

57 Véase, Taruffo (2008), p. 56 y 57: "Por consiguiente, el derecho a presentar todos los medios de prueba relevantes que estén al alcance de las partes es un aspecto esencial del derecho al debido proceso y debe reconocerse que pertenece a las garantías fundamentales de las partes". 
que igualmente ha sido recepcionado por sistemas jurídicos románicoscontinentales al constituir una respuesta frente a problemáticas comunes.

Parece claro que, en el derecho procesal penal iberoamericano, la exclusión de prueba de baja calidad epistémica se ha de articular sobre la base del concepto de prueba útil o inútil o prueba idónea o inidónea. Y, desde esta perspectiva, parece un esfuerzo innecesario en la materia realizar definiciones estipulativas o disquisiciones basadas en categorías anglosajonas, especialmente cuando no se fundamenta el cambio de nomenclatura.

La relación que se pueda hacer entre los contenidos del fallo Daubert y los conceptos continentales de prueba útil o idónea generan dos grandes cuestionamientos: ¿ es posible excluir prueba de baja calidad epistémica en los casos de ordenamientos que no contengan expresamente la posibilidad respecto de la prueba inútil o inidónea? Por otro lado, en aquellos ordenamientos que sí contengan dicha hipótesis de exclusión,

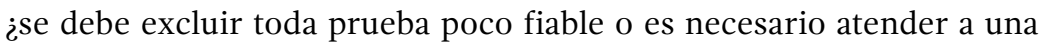
gradualidad para excluir la prueba manifiestamente poco fiable?

Ambos cuestionamientos están permeados por cómo se insertan las reglas de exclusión en el sistema de normas probatorias, especialmente, en lo que refiere a la admisibilidad.

A mi modo de ver, el derecho a la prueba en relación con el debido proceso son fuertes antecedentes para asumir que el principio en la materia es la libertad de incorporación de medios de prueba y, solo por excepción, la exclusión de la misma en sede de admisibilidad. Este es el principio general reafirmado por la historia de las instituciones procesales de cuño románico-continental. Además, porque pueden haber cuestiones competenciales de por medio (por lo demás no ausentes en el common $l a w^{58}$ ), pues -como se afirma en Alemania-hay que ser cauteloso con la exclusión de la prueba inútil en sede de admisibilidad, porque ello puede significar un adelantamiento de la valoración probatoria propia de la fase de juicio ${ }^{59}$. Por lo demás, es conocida la tendencia probatoria de la Revolución Francesa a favorecer las "libertades" en materia de prueba, pues parecía ser que ello era una cuestión demasiado compleja para

58 Véase, Denbeaux/Risinger (2003), p. 23.

59 Kühne (2015) p. 508. 
someterla a las riendas del legislador y sujetarla a corsés normativos ${ }^{60}$. En efecto, como bien nos aporta la discusión en el ámbito anglosajón, la "probabilidad de alcanzar una decisión correcta respecto de la verdad sobre los hechos aumenta en la medida en que lo hace la información de lo ocurrido" ${ }^{61}$. Según Ferrer, el principio esencial en sede de admisibilidad es la de obtener un conjunto de prueba lo más rico posible, entendiendo que ello se satisface cuando el proceso judicial facilita la incorporación al proceso del máximo número de pruebas relevantes ${ }^{62}$. Según Laudan, "excluir pruebas relevantes, y no redundantes, por la razón que sea, disminuye la probabilidad de que personas, en principio, racionales lleguen a conclusiones correctas" ${ }^{63}$.

En sede continental, el alcance de las reglas que rigen la admisión probatoria, si bien contemplaban fundamentos epistémicos, no son ni los únicos ni los más importantes. También está presente la intención de limitar las facultades judiciales, la economía procesal, y la correcta inversión de los fondos públicos en la administración de justicia. Sin embargo, abundante literatura pone de manifiesto que los ideólogos de la Revolución Francesa tuvieron acceso a las obras inglesas ${ }^{64}$, por lo que no sería nada de raro que las reglas de exclusión probatoria en el ámbito continental tengan como antecedentes obras anglosajonas, como las de Bentham.

Ahora, desde el punto de vista epistémico, el fallo Daubert atribuye al juez de la fase intermedia (que conoce de la admisibilidad) el rol de "guardian" o "gatekeeper" de la prueba, función a partir de la cual tiene como tarea retener los antecedentes de baja calidad epistémica. Sin afirmarlo expresamente, el fallo Daubert asume que un jurado compuesto por legos o laicos presenta menores competencias cognitivas que un solo juez letrado para reconocer una prueba pericial científica de mala calidad, que pueda estar amparada por el sesgo de la "cientificidad" o

60 Damaska (2015), p. 37.

61 Ferrer (2010), p. 12; Laudan (2013), p. 46. Ferrer (2007), p. 68.

62 Ferrer (2007), p. 68.

63 Laudan (2013), p. 46.

64 Andrés (1992), p. 279; Vásquez Sotelo (1984), p. 456. 
"mito de la infalibilidad" 65 antes señalado. Por ello se haría necesario adoptar un cierto paternalismo epistémico para proteger al jurado de creencias equivocadas. Con ello el fallo Daubert transfiere la problemática de la prueba científica desde la valoración que hace el jurado hacia la admisibilidad de la prueba ${ }^{66}$.

Lo anterior, a mi parecer, no es replicable en los jueces de las fases intermedias en los ordenamientos jurídicos continentales, entre otras razones, por diferencias contextuales importantes como la esencialidad de la justicia por jurados en el common law ${ }^{67}$, a diferencia de lo que sucede en el ámbito del civil law con algunas excepciones (p. ej., procedimiento por Jurado en España, Argentina y Brasil). La cuestión no es baladí, pues el jurado no debe motivar su veredicto, por lo que es dable suponer que los sesgos de la prueba pericial puedan llegar a ser más intensos que aquellos presentes en jueces que deben motivar la valoración probatoria que realizan ${ }^{68}$ operando, esto último, como un mecanismo de control indirecto de la calidad epistémica de la prueba. En Chile, en materia penal, el Tribunal del Juicio Oral en lo Penal debe hacerse cargo de toda la prueba producida, incluso de aquella que hubiere desestimado, indicando en tal caso las razones que hubiere tenido en cuenta para hacerlo (artículo 297 inciso final Código procesal penal chileno).

En estrecha relación con lo anterior, también hay que destacar que el fallo Daubert asume como modelo implícito de pericia fiable aquella proveniente de las ciencias duras (especialmente prueba de $\mathrm{ADN}^{69}$ ), lo

${ }_{65}$ Gascón (2013), p. 182. Para Dwyer (2008), p. 2.

${ }^{66}$ Dwyer (2008), p. 2.

67 Según Fletcher y Sheppard, el jurado consiste en doce personas legas, no adiestradas en el derecho, que tiene el poder de deliberar sobre la base de la prueba y decidir la responsabilidad de las partes en juicio civil, o sobre la culpabilidad o inocencia en el juicio penal, en ambos casos, por el voto de la unanimidad de sus miembros o cerca de la misma. Véase, Fletcher y Sheppard, (2005), p. 245. En el mismo sentido, respecto de la diferencia entre los sistemas jurídicos, véase, Bachmaier (2009), pp. 119 ss; Jimeno (2013), pp. 217 ss. Así, Duce (2010), p. 49.

69 Berger (2011), p. 129: "Daubert and DNA match very well. Indeed, it has been suggested that the advent of DNA profiling may have paved the way for the Supreme Court's opinion in Daubert". En este sentido, Faigman, (2001), p. 111. 
cual dificulta su aplicación a productos derivados de las ciencias sociales, humanas o "blandas", incluso cuando posterior al fallo se extendió su aplicación a ámbitos técnicos ${ }^{70}$. Taruffo señala que sería necesario una especie de "Daubert" de las ciencias no empíricas, con el objetivo de establecer un conjunto de reglas que puedan ser aplicadas por los jueces para controlar la validez de los conocimientos ofrecidos por esa ciencia y su utilidad probatoria ${ }^{71}$. Pero además, y dejando al margen lo anterior, es posible afirmar que en un proceso penal tipo, con jueces legos, donde se conoce de la exclusión probatoria en la fase intermedia, el juez a cargo de decidir la admisión probatoria enfrenta variados problemas que cuestionan la posibilidad de encontrarse en una "mejor posición epistémica" para detectar la prueba de baja calidad en relación con los jueces que conocen del juicio oral. Por ejemplo, en la fase de admisión probatoria está ausente la posibilidad de valorar conjuntamente o de forma coherencial los medios de prueba $^{72}$, precisamente porque ellos no se han rendido aún. De igual forma, no existe un periodo de prueba sobre alguna discusión que pueda darse en relación con la admisión de determinados medios de prueba ("prueba sobre prueba"). Por último, es muy difícil que un juez se forme una opinión sobre la calidad epistémica de la pericia si las pruebas no se han rendido aún ni han sido incorporadas a juicio de forma contradictoria y resguardando el derecho de defensa del imputado. Por todo lo anterior se ha dicho que la decisión de admisibilidad del medio de prueba solo puede resolverse hipotéticamente ${ }^{73}$.

Así, todo lo que tenga que ver con la valoración de la prueba y la decisión del asunto, en un contexto normativo que obligue a los jueces a motivar sus decisiones, no debe ser abordado anticipadamente en el

Gascón (2013), p. 181 señala: "Los avances han sido particularmente espectaculares en el campo de la genética forense, que ha marcado un antes y un despúes en la resolución de numerosos problemas judiciales, como la investigación biológica de la paternidad, la identificación de personas o la investigación de indicios, es decir, el análisis de muestras biológicas de interés criminal, como manchas de sangre, saliva, esperma o pelos".

Taruffo (2013) p. 208.

71 Taruffo (2008), p. 286. En el mismo sentido, Sánchez (2019), pp. 238 y s.

72 Valenzuela (2017), p. 105.

73 Taruffo (2008), p. 39. 
momento de la selección del material probatorio ${ }^{74}$. Aun cuando se pudiere llegar a hacer un uso abusivo del carácter "pericial" de ciertas pruebas en el juicio-que sucede lamentablemente más a menudo de lo que fuera deseable-no estoy seguro que dicha cuestión práctica pueda ser una limitante jurídicamente justificada para la libertad de incorporación de medios de prueba en el marco de la finalidad de la búsqueda de la verdad de lo sucedido. Mas bien parece un riesgo a tolerar, especialmente si el ordenamiento jurídico dispone de medidas de contención en la fase de juicio oral.

Todo lo expresado anteriormente fundan razones atendibles para estimar, en el ámbito continental, que la libertad de prueba o libertad de incorporación de la prueba es la regla general frente a la cual hacen excepción las reglas de exclusión. Estas últimas, con un manifiesto carácter restrictivo ${ }^{75}$ por afectar el derecho a la prueba.

Así, por ejemplo, en el artículo 148 del Código procesal penal modelo para Iberoamérica se señala que "se podrá probar todos los hechos y circunstancias de interés para la correcta solución del caso y por cualquier medio de prueba permitido", agregando luego que "un medio de prueba, para ser admitido, debe referirse, directa o indirectamente, al objeto de la averiguación y ser útil para el descubrimiento de la verdad". De igual forma, se puede predicar de la fase intermedia del proceso penal chileno que contiene una cláusula de cierre ratificando la libertad de incorporación de prueba: "Las demás pruebas que se hubieren ofrecido serán admitidas por el juez de garantía al dictar el auto de apertura del juicio oral” (art. 276 parte final CPP chileno) Por lo demás, y a mayor abundamiento, este es un principio que también se encuentra contenido en las FRE, de cual la decisión Daubert interpreta una de sus normas. El artículo 402 del mismo dispone: "Relevant evidence is admissible unless any of the following provides otherwise: the United States Constitution; a federal statute; these rules; or other rules prescribed by the Supreme Court. Irrelevant evidence is not admissible". En efecto, la provisión de que toda la prueba relevante es admisible, con ciertas excepciones, y que la prueba que no es relevante no es admisible, "es una presuposición contenida en toda la concepción de un sistema de

74 Ferrer (2007), pp. 42 ss.

75 Así, también, Cordero (2000), p. 46. 
prueba racional"76. Desde esta perspectiva, no solo cuestiones normativojurídicas sino también epistémicas aconsejan asumir como principio que "toda prueba relevante es admisible", y solo excepcionalmente no lo es cuando haya referencia legal expresa al respecto basada en la protección de intereses extraepistémicos.

\section{4. ¿Es posible la recepción del fallo Daubert en los procesos PENALES ROMÁNICO-CONTINENTALES?}

La decisión Daubert equipara conocimiento científico ("scientific knowledge") con fiabilidad ("reliability") ${ }^{77}$, cuestión que es criticada por Haack, entre otras razones, por el carácter honorífico que puede otorgarse al términos científico, en cuyo caso se generaría una tautología y una asimilación injustificada entre estos dos conceptos. Siendo así, la fiabilidad como criterio no permitiría discriminar entre buena o mala ciencia ${ }^{78}$. De otro lado, si la cientificidad se utiliza en un sentido descriptivo, se podría generar el problema de la imposibilidad de atribuir incompetencias o falencias epistémicas a los exponentes de ciencias "duras", en circunstancias que expertos de ciencias no empíricas pueden llegar a ser serios e investigadores fiables. Según la misma autora: “... not all, and not only, scientist are reliable inquirers; and not all, and not only, scientific evidence is reliable"79. Así, la epistemóloga destaca que "la ciencia tiene una posición epistémica distinguida, pero no privilegiada" ${ }^{80}$.

76 Thayer (1898), p. 264.

77 Según Ndreu (2006), p. 464., la decisión Daubert equipararía fiabilidad ("reliability") con veracidad ("trustworthiness")

78 Haack (2014), p. 111: "if «scientific» is used honorifically, it is tautology that genuinely scientific evidence is reliable; but trivial verbal truth is of no help to judge trying to screen proffered scientific testimony for reliability".

79 Ibid, p. 111.

80 Haack (1997), p. 189. Agrega: "Según nuestros criterios de evidencia empírica ha sido, en general, una tentativa cognoscitiva con éxito. Pero es falible, revisable, imcompleta e imperfecta; y al juzgar dónde ha tenido éxito y dón de ha fallado, en qué áreas y en qué momentos es epistémicamente mejor o peor, recurrirmos a criterios que no son intrínsecos de la ciencia ni simplemente determinados por ella". 
Si bien es cierto la decisión Daubert, con sus fundamentos epistémicos, logra instalar en la discusión de la admisibilidad probatoria el criterio de la fiabilidad, deja abierta la cuestión del sentido y alcance del concepto. Se dan algunos indicadores, pero bajo ningún punto se resuelve la cuestión de forma concluyente. Ahora, ello no necesariamente es del todo inconveniente, pues esa misma amplitud permite a los jueces la emisión de decisiones sobre admisibilidad mucho más depuradas y sofisticadas ${ }^{81}$. Precisamente es la complejidad de la cuestión, y su amplitud, la que no ha logrado del todo instalar en la jurisprudencia norteamericana el criterio de la fiabilidad como filtro de admisión ${ }^{82}$. Sin embargo, creo injusto descartar del todo en nuestros ordenamientos románico-continentales el criterio de fiabilidad que sugiere la decisión, aunque de todas maneras con un carácter restringido ${ }^{83}$. Entre otras razones, por la potencia normativa del derecho a la prueba y por las diferencias contextuales donde nace la fiabilidad como criterio que dota de contenido a la regla de exclusión de la FRE.

El fallo Daubert ha hecho gráfica una cuestión escasamente tratada por el derecho procesal continental: los sesgos que puede producir en la decisión judicial ciertos dictámenes periciales de baja calidad epistémica. Quizá ha sido una cuestión escasamente tratada o advertida en sede continental, entre otras razones, por la oficialidad, imparcialidad ${ }^{84}, \mathrm{y}$ cierta "neutralidad" que asiste a los peritos cuando se considera que presentan una posición auxiliar a la función jurisdiccional ${ }^{85}$ (facilitadores de conocimiento experto necesario para la resolución del objeto del juicio).

Sin embargo, los criterios de solución que se han ofrecido a partir del fallo Daubert, a mi parecer, no son del todo consistentes para

${ }^{81}$ Sanders (2003), p. 938.

82 Sanders (2003), p. 938.

83 Así también, Sánchez (2019), p. 241.

${ }^{84}$ Véase, Vázquez (2015), p. 140.

85 Por ejemplo, Gimeno Sendra señala que el informe pericial es un acto de investigación o prueba por el que determinados profesionales cualificados por sus especiales conocimientos científicos, técnicos o artísticos y designados por el Juez, le “...auxilian o aportan máximas de la experiencia, de las que pudiere carecer, a fin de obtener una mejor comprensión sobre la naturaleza y tipicidad del hecho, así como la responsabilidad penal del autor”.Véase, Gimeno (2008), p. 310. 
adoptarse in toto en nuestros ordenamientos jurídicos. Especialmente cuando existen en el Derecho procesal continental conceptos doctrinales que intentan dar una solución a la problemática planteada como el de prueba "idónea" o prueba "útil", y parecen tener un mejor rendimiento bajo el prisma sistemático jurídico de las reglas que se ocupan de la prueba en los procesos judiciales de herencia románica-continental.

¿Ello significa que el "fallo Daubert" es insignificante para la exclusión de la prueba pericial de baja calidad epistémica en nuestros ordenamientos procesales penales?

No. También en esto hay que ser cautos. Si bien en el ámbito continental era conocida la inadmisión de prueba pericial por baja calidad epistémica, las reglas parecían girar sobre la base de la ausencia de ciertas características del perito, con un carácter muy particular.

El principal rendimiento "continental" del fallo Daubert, a mi modo de ver, se dará en la fase de valoración probatoria pues, en realidad en los sistemas del civil law, ese es el verdadero momento en que la validez científica de las pruebas es evaluada por el juez ${ }^{86}$. Esta es la posición que, hasta el momento, se ha sostenido en los países europeos ${ }^{87}$. Sin embargo, ello no impide que la discusión del fallo Daubert también pueda aportar ciertas luces en la fase de admisión, especialmente en los casos de ordenamientos jurídicos que cuentan en sus procesos penales con un momento de selección de prueba distinto al del juicio oral. Igualmente, en aquellos países iberoamericanos que cuentan con enjuiciamientos por jurado.

En efecto, el concepto de fiabilidad puede servir para dotar de contenido al término de prueba pericial "útil" o "idónea", pero solo en un sentido débil. Es decir, a partir de todo lo expresado, una prueba pericial manifiestamente poco fiable puede ser considerada una prueba inútil o inidónea. Y ello acaece, a mi modo de ver, cuando el sustento teórico en el cual se basa la disciplina de la cual es parte el dictamen pericial impide que las conclusiones aporten algún tipo de probabilidad lógica o cuantitativa en relación con el grado de confirmación de los hechos discutidos en el pleito. Ello, ya sea en el caso concreto, ya sea porque ex

\footnotetext{
86 Taruffo (2008), p. 100.

87 Sánchez (2019), p. 214.
} 
ante el área disciplinar no es capaz de ofrecer el resultado esperado en relación con la corroboración del enunciado fáctico. Esto es lo que sucede con el polígrafo o con los peritajes psicológicos de credibilidad de adultos.

La "debilidad" de la noción de fiabilidad para ser un filtro de exclusión contundente puede justificarse, entre otras razones, en los elevados problemas epistémicos que presenta dicho concepto en relación con el resto de derechos que asisten a las partes en relación con la prueba. A este respecto, por ejemplo, Stein pone en relación la calidad epistémica de la prueba con ciertos derechos que asisten al imputado, afirmando que la prueba científica que no logre satisfacer el estándar Frye debe ser excluida siempre que se rinda en contra del acusado en juicio criminal ${ }^{88}$.

Otro de los cuestionamientos epistémicos que aconsejan una cierta cautela en la exclusión de la pericia científica poco fiable es la asunción de que el conocimiento científico presenta una mayor solidez epistémica que el conocimiento no científico, cuestión que la doctrina ya observa como algo dudoso o erróneo ${ }^{89}$, según afirmaba. Es decir, el análisis de la fiabilidad de la pericia no debiera ser algo muy distinto al análisis general de la calidad epistémica de otras pruebas, - no científicas - como la prueba testimonial, sobre la base de la superación de la creencia y de la coherencia ${ }^{90}$. En este sentido, no hay razones epistémicas que justifiquen que la opinión de expertos sea valorada de una forma separada a como se entienden probados los hechos por medios de prueba basados en conocimiento no experto $^{91}$. Lo que un experto aporta son consejos especializados sobre las generalizaciones apropiadas para aplicar a un conjunto particular de hechos, y cómo esas generalizaciones deberían aplicarse mejor, así como la propia conclusión del experto sobre la aplicación de esas generalizaciones ${ }^{92}$. Desde esta perspectiva, el no experto puede como mínimo observar

88 Stein (2013), p. 257.

Gascón (2013), p. 183.

Valenzuela (2017), p. 106.

Dwyer (2008), p. 75. En contra, Nieva (2010), p. 285.

Dwyer (2008), p. 78. Agrega: "To talk about evidence of opinion as being quite distinct from evidence of fact may therefore have been a wrong turn in the development of evidence jurisprudence. It creates unnecessary difficulties for us in forming a correct understanding of how the court assesses evidence, and particularly expert evidence”. 
cómo la credibilidad, la relevancia y el peso probatorio de ciertos nodos o átomos se utilizan en el argumento y se combinan con las diversas líneas de inferencias, sin comprender necesariamente si la prueba y la valoración realizada por el experto es semánticamente correcta ${ }^{93}$. Esto, por lo demás, es bastante coherente con la asunción de Haack acerca de que el método científico no es más que un refinamiento del pensamiento cotidiano ("a refinement of everyday thinking") 94 . En este sentido, no existe un método científico (exclusivamente científico) como se asume en el fallo Daubert ${ }^{95}$. De ahí que solo sea factible y aceptable jurídicamente que, si se desea emplear la falta de fiabilidad como criterio de exclusión de la prueba pericial en sede de admisibilidad, esta deba estar referida a casos claros, debiendo admitirse la prueba pericial frente a la duda sobre la fiabilidad epistémica. En términos Hartianos, la exclusión de la prueba pericial por inutilidad debiera estar referida al núcleo semántico de la expresión "falta de fiabilidad epistémica" y no extenderse a los casos que pudieran situarse en la zona de penumbra o periferia difusa.

Por lo demás, lo anterior se aviene de mejor forma con que la titularidad jurisdiccional de la decisión acerca de los hechos recaiga en el juez y no en el perito. En el ámbito continental se expresa lo anterior con el brocardo latino que grafica la posición del juzgador frente al experto: el juez es, precisamente, peritum peritorum ${ }^{96}$. De igual forma es coherente con la importancia que en nuestros sistemas de enjuiciamientos tiene la libertad de incorporar medios de prueba como corolario del derecho a la prueba y del debido proceso.

Una amplitud normativa de la regla de exclusión que nos permita excluir cualquier caso de pericia científica cuya fiabilidad se ponga en duda puede generar un "sesgo de admisibilidad" de aquellas pruebas que hayan pasado el filtro, que puede afectar a los jueces que conocen del juicio oral. El peligro de ello es que una pericia declarada admisible, por ser tal, puede llevar a creer que ya no es necesario su análisis en cuanto prueba, de la metodología empleada, de sus conclusiones, de la forma

\footnotetext{
93 Dwyer (2008), p. 100.

94 Haack (2003), p. 93 ss.

95 Haack, (2014), p. 111.

96 Véase, Muñoz Sabaté (2016), p. 86.
} 
como apoya un determinado enunciado fáctico y, finalmente, como ello es utilizado por el juez en su decisión sobre los hechos ${ }^{97}$. Lo anterior, por supuesto, no es admisible en el diseño continental de la decisión fáctica cuya titularidad jurisdiccional exclusiva recae en el juez, y no puede adelantarse a la fase de admisibilidad.

\section{Conclusiones}

La prueba pericial científica cada vez más está presentando importancia en los procesos judiciales. Ello, sería una consecuencia de la relevancia social que ha experimentado el conocimiento experto, que ha penetrado en diversas áreas del desenvolvimiento de las personas. El aumento exponencial de áreas de especialización funcional, con el consiguiente aumento de especialista en dichos ámbitos, ha generado la necesidad de emplear criterios que nos permitan distinguir entre "buena" o "mala" ciencia, con el objeto de extraer de los procedimientos judiciales la prueba pericial científica de baja calidad epistémica. Ello, con la finalidad de evitar una decisión errónea sobre los hechos basadas en las mismas probanzas, como resultado de la operatividad del "mito de la infalibilidad"980 "sesgo de cientificidad".

En el ámbito anglosajón, la decisión Daubert v. Merrel Dow Pharmaceuticals de la Corte Suprema de los Estados Unidos, constituye un "leading case" que se refiere a los criterios de fiabilidad o cientificidad de la prueba pericial científica, cuya ausencia genera la posibilidad de excluir la prueba en fase de admisibilidad.

97 Berger (2011), p. 1125: "When the evidence is admitted it is then labeled "reliable" because, according to Daubert, expert testimony must be reliable in order to be deemed admissible. That should not, however, mean that no further analysis of the evidence is required. Admissibility and sufficiency determinations rest on more than satisfaction of a reliability component; they require careful attention to what the evidence proves and how the trier of fact will use it". En el mismo sentido, Sánchez (2019), p. 242, llama a ser cuidadosos en aplicar los criterios Daubert pues, con ello, se puede imponer un doble examen respecto de la prueba científica, a diferencia de lo que sucedería con el resto de las pruebas. Para mí, ello podría abonar la creación de un sesgo de admisión respecto de la prueba pericial que ha superado el filtro de admisibilidad.

Gascón (2013), p. 182. 
Las problemáticas que refleja el fallo Daubert son generales y aplicables a todas las tradiciones jurídicas, por lo que merece la pena preguntarse si el desarrollo contenido en dicha decisión puede o no ser aplicable a los procesos penales de la tradición románica-continental.

El derecho procesal continental ha abordado la cuestión de la exclusión de la prueba sobre la base de los conceptos de pertinencia, prueba idónea, prueba útil, prueba relevante. En especial, la inadmisión sobre la base de la baja calidad epistémica de la pericia es una cuestión que ha tratado de forma más precisa a través de los conceptos de prueba útil y/o idónea, entendido ello como la capacidad del medio de prueba de aportar información epistémica relevante para la prueba de los hechos del caso, en relación con el establecimiento de un cierto grado de probabilidad ya sea lógica o cuantitativa.

En consideración a lo anterior se puede establecer una relación entre el concepto de fiabilidad epistémica de la prueba pericial, derivada de la cientificidad discutida en el fallo Daubert, y la noción de utilidad y/o idoneidad de la prueba en el ámbito continental. Sin embargo, se hace necesario precisar los alcances del vínculo, especialmente por la gradualidad ínsita a la estimación de la capacidad epistémica de los medios de prueba que se pueden aportar a los procesos judiciales.

A mi parecer, el derecho a la prueba en relación con el debido proceso son fuertes antecedentes para asumir que el principio en la materia es la libertad de incorporación de medios de prueba y, solo por excepción, la exclusión de la misma en sede de admisibilidad. Este es el principio general reafirmado por la historia de las instituciones procesales de cuño románico-continental, con una gran cantidad de manifestaciones positivas, y por lo demás algo no desconocido para la tradición probatoria del common law.

De otro lado, las diversas críticas que se han hecho a los presupuestos epistémicos del fallo Daubert aconsejan, sin desconocer su importancia en la materia, ser cautelosos a la hora de fundar exclusiones probatorias en sus asunciones.

Así, la respuesta al cuestionamiento origen de este trabajo es afirmativa: el fallo Daubert sí presenta un rendimiento en sede de admisibilidad en nuestros ordenamientos procesales penales de la tradición románica-continental. Pero ello debe matizarse. 
Si se quiere utilizar la falta de fiabilidad y/o cientificidad como criterio de exclusión epistémica de la prueba pericial, esta solo debe estar referida a casos claros, reservándose la valoración de los casos dudosos para la fase de juicio oral. En otras palabras, la exclusión de la prueba pericial por inutilidad está referida al núcleo semántico del concepto "falta de fiabilidad epistémica" y no se extiende a los casos que pudieran situarse en la zona de penumbra o periferia difusa. Esta conclusión, por lo demás, es coherente con que la titularidad jurisdiccional sobre la decisión de los hechos recaiga sobre el Tribunal que conozca del juicio oral, impidiéndose con ello que la admisibilidad probatoria se transforme en un prejuzgamiento de la cuestión.

En todo caso, las diversas prerrogativas en juego-especialmente el derecho a la prueba- generan que deben ser declaradas admisibles en juicio las pericias que aporten un dato que este referida a la determinación de la probabilidad de acaecimiento de la hipótesis, aunque sea en un mínimo grado. Será materia de juicio oral determinar si esta pericia podrá ser una prueba que aporte datos que permitan una condena más allá de toda duda razonable, cuestión que sin duda no puede ser abordada adecuadamente en sede de admisibilidad.

\section{Biblografía}

Alcoceba, Juan (2018) Los estándares de cientificidad como criterio de admisibilidad de la prueba científica. Rev. Bras. de Direito Processual Penal, Porto Alegre, vol. 4, n. 1, pp. 215-242. https://doi.org/10.22197/rbdpp.v4i1.120

ANDRÉs, Perfecto (2015) Tercero en discordia. Madrid: Trotta.

BACHMAIER, Lorena (2009) Dos modelos de prueba pericial penal en el derecho comparado: Estados Unidos de Norteamérica y Alemania. Jueces para la Democracia, Madrid, n. 66, pp. 118-137.

Berstein, David, (2008) Expert witnesses, adversarial bias, and the (partial) failure of the Daubert revolution. Iowa law review, Iowa, v. 93, pp. 102-137.

BERGER, Margaret (2003) Expert testimony in criminal proceedings: questions Daubert does not answer, Seton Hall Law review, South Orange, vol. 33, pp. 1125-1140. 
Binder, Alberto (1999) Introducción al Derecho procesal penal. $2^{\circ}$ edición. Buenos Aires: Ad-hoc.

CAFFERATA, José (1998) La prueba en el proceso penal. $3^{\circ}$ edición. Buenos Aires: Ediciones Depalma.

Cordero, Franco (2006) Procedura penal. Ottava edizione. Milano: Giuffrè.

Damaska, Mirjan (2015) El derecho probatorio a la deriva, (trad.) Joan Picó. Madrid, Barcelona, Buenos Aires, Sao Paulo: Marcial Pons.

Denbeaux, Mark/ Risinger, D. (2003) Kumho Tire and Expert Reliability: How the Question You Ask Gives the Answer You Get. Seton Hall Law Review, South Orange, vol. 34: Iss. 1, Article 2, pp. 15-75.

Devis Echandía, Hernando (1988) Teoría general de la prueba judicial. Tomo II. Buenos Aires: Zavalia.

Duce, Mauricio (2010): Admisibilidad de la prueba pericial en juicio orales: un modelo para armar en la jurisprudencia nacional. In: Accatino, Daniela (coord), Formación y valoración de la prueba en el proceso penal. Santiago: Legalpublishing, pp. 45-86.

DWYER, Déirdre (2008) The judicial assessment of expert evidence. Cambridge: Cambridge University Press. https://doi.org/10.1017/cbo9780511575136.

Faigman, David (2001) The Tipping Point in the Law's Use of Science: The Epidemic of Scientific Sophistication That Began with DNA Profiling and Toxic Torts. Brooklyn Law Review., Brooklyn, vol. 67, pp. 111-125.

Fletcher, George/Sheppard, Steve (2005): American Law in a global context. Oxford: Oxford University Press.

FERrer, Jordi (2005): Prueba y verdad en el Derecho. $2^{\circ}$ edición. Madrid, Barcelona, Buenos Aires: Marcial Pons.

FERRER, Jordi (2007): La valoración racional de la prueba. Madrid, Barcelona, Buenos Aires: Marcial Pons.

FERRER, Jordi (2010) La prueba es libertad, pero no tanto: una teoría de la prueba Cuasi-Benthamiana. In: AcCATino, Daniela (coord), Formación y valoración de la prueba en el proceso penal. Santiago: Legalpublishing, pp. 3-19. 
Gardner, Thomas/Anderson, Terry (2013) Criminal Evidence. Wadswoth: Cengage Learning.

Gascón, Marina (2013) Prueba científica. Un mapa de retos. In: VÁzQuEz, Carmen (ed.) Estándares de prueba y prueba científica. Madrid/Barcelona/Buenos Aires/ Sao Paulo: Marcial Pons. pp. 181-201.

Gimeno, Vicente (2008) Manual de Derecho procesal penal. Madrid: Colex.

GöвEL, Klaus (2013) Strafprozess. 8 Auflage. München:Verlag C.H. Beck.

HaAck, Susan (1997) Evidencia e investigación. Trad. María Ángeles Martínez García. Madrid: Tecnos.

HaAck, Susan (2003) Defending Science. New York: Prometheus Books.

HAACK, Susan (2014) Trial and error: two confusions in Daubert. In HaAck, Susan, Evidence matters. Cambridge University Press. New York. pp. 104-121. https://doi.org/10.1017/CBO9781139626866

INGRAM, Jefferson (2012) Criminal Evidence. $11^{\text {th }}$. Edition. Waltham: Elsevier. https://doi.org/10.4324/9781315721873

JAUChen, Eduardo (2006) Tratado de la prueba en materia penal. Buenos Aires: Rubinzal-Culzoni.

Jimeno, Mar (2013) El proceso penal en los sistemas del common law y civil law: los modelos acusatorios e inquisitivo en pleno siglo XXI. Justicia, Barcelona, № 2, pp. 201-304.

KINDHÄUSER, Urs (2006) Strafprozessrecht. Baden-Baden: Nomos.

KüHNE, Hans-Heiner (2015) Strafprozessrecht. 9. Ausflage. Heilderberg: C.F. Müller.

MAIER, Julio (1996) Derecho procesal penal. $2^{\circ}$ edición. T.III. Buenos Aires: Del Puerto.

May, Richard (1999) Criminal Evidence. London: Sweet \& Maxwell.

Montero, Juan (2005) La prueba en el proceso civil. $4^{\circ}$ edición. Madrid: Thomson/ Civitas.

MonTón, Lidón (1999) La admisión y práctica de la prueba en el proceso penal. Madrid:Trivium. 
Mittermaier, Karl Joseph Anton (2006) Tratado de la prueba en materia criminal. Trad. Primitivo González. Buenos Aires: Hammurabi.

MuÑoz SABATÉ, Lluis (2016) La prueba de indicios en el proceso judicial. Madrid: Wolters Kluwer.

Nieva, Jordi (2010): La valoración de la prueba. Madrid, Barcelona, Buenos Aires: Marcial Pons.

NDREU, Dije (2006) Keeping bad science out of the coutroom: why post-daubert courts are correct in excluding opinions based on animal studies from birth defects cases. Golden Gate University Law Review, San Francisco, vol. 36, pp. 459-488.

Peters, Karl (1985) Strafprozess. 4 Auflage. Heilderberg: C.F. Müller Juristischer Verlag.

Picó, Joan (2008) El juez y la prueba. Barcelona: J. M. Bosch.

Roberts, Paul/Zuckerman, Adrian (2010) Criminal evidence. Oxford: Oxford University Press.

Roxin, Claus (2000) Derecho procesal penal. Trad. Gabriela Córdoba y Daniel Pastor. Buenos Aires: Editorial del Puerto.

SÁnCHEz, Ana (2019) La prueba científica en la justicia penal. Valencia: Tirant lo Blanch.

SANDERS, Joseph (2003) The merits of the paternalistic justification for restriction on the admissibility of expert evidence. Seton Hall Law Review, South Orange, vol 33, p. 881-941.

Serra Domínguez, Manuel (1969) Contribución al estudio de la prueba. In: Serra, Manuel, Estudios de Derecho procesal. Barcelona: Ediciones Ariel.

Stein, Alex (2013): Foundations of Evidence Law. Oxford: Oxford University Press. https://doi.org/10.1093/acprof:oso/9780198257363.001.0001

Stein, Friedrich (1990): El conocimiento privado del juez. Trad. Andrés de Oliva. $2^{\circ}$ edición castellana. Madrid: Editorial Centro de Estudios Ramón Areces.

ThAYER, James (1898) A preliminary Treatise on Evidence at the common law. Boston: Little, Brown and Company. 
TARuffo, Michele (2008) La prueba. Madrid, Barcelona, Buenos Aires: Marcial Pons. TARUffo, Michele (2009) La prueba de los hechos. $3^{\circ}$ edición. Madrid: Trotta. TARuffo, Michele (2011) La motivación de la sentencia civil. Trad. Lorenzo Cordova. Madrid: Trotta.

TARUfFo, Michele (2013) La aplicación de estándares científicos a las ciencias sociales y forenses. In: VÁzQuez, Carmen (ed.) Estándares de prueba y prueba científica. Madrid/Barcelona/Buenos Aires/Sao Paulo: Marcial Pons.

VALEnZUela, Jonatan (2017) Los mitos de la prueba pericial en el proceso penal chileno. In: Valenzuela, Jonatan. Hechos, pena y proceso. Santiago: Rubicón.

VÁzQuez, Carmen (2015) De la prueba científica a la prueba pericial. Madrid/ Barcelona/Buenos Aires/Sao Paulo: Marcial Pons.

Vega, Jaime (1993) Presunción de inocencia y prueba en el proceso penal. Madrid: La Ley.

Vera SÁnchez, Juan Sebastián (2017) Naturaleza jurídica de la Fase Intermedia del proceso penal chileno. Un breve estudio a partir de elementos comparados, Revista de Derecho de la Pontificia Universidad Católica de Valparaíso, N49, pp. 141-184.

Vera SÁnchez, Juan Sebastián (2018) Ciertas dudas que deja el fallo Daubert. Comentario al capítulo segundo de la monografía de Carmén Vázquez "De la prueba científica a la prueba pericial”. Anuario de Filosofía Jurídica y Social, Santiago, $\mathrm{N}^{\mathrm{o}} 34$, pp. 43-59.

VoLk, Klaus (2002) Strafprozessrecht. $3^{\circ}$ Auflage. München: Verlag C.H.Beck. 


\section{Additional information and author's declarations (scientific integrity)}

Conflict of interest declaration: the author confirms that there are no conflicts of interest in conducting this research and writing this article.

Declaration of authorship: all and only researchers who comply the authorship requirements of this article are listed as authors; all coauthors are fully responsible for this work in its entirety.

Declaration of originality: the author assures that the text here published has not been previously published in any other resource and that future republication will only take place with the express indication of the reference of this original publication; he also attests that there is no third party plagiarism or self-plagiarism.

\section{Dados do processo editorial}

(http://www.ibraspp.com.br/revista/index.php/RBDPP/about/editorialPolicies)

- Recebido em: 15/12/2020

- Controle preliminar e verificação de plágio: 04/01/2021

- Avaliação 1: 14/01/2021

- Avaliação 2: 25/01/2021

- Avaliação 3: 26/01/2021

- Avaliação 4: 26/01/2021

- Decisão editorial preliminar: 02/02/2021

- Retorno rodada de correções: 17/02/2021

- Decisão editorial final: 18/02/2021
Equipe editorial envolvida

- Editor-chefe: 1 (VGV)

- Editora-associada: 1 (KK)

- Revisores: 4 


\section{COMO CITAR ESTE ARTIGO:}

VERA SÁNCHEZ, Juan Sebastián. Exclusión de la prueba pericial científica (de baja calidad epistémica) en fase de admisibilidad en procesos penales de tradición románica-continental: Diálogo entre dos culturas jurídicas. Revista Brasileira de Direito Processual Penal, Porto Alegre, vol. 7, n. 1, p. 375-408, jan./abr. 2021. https://doi.org/10.22197/rbdpp.v7i1.498

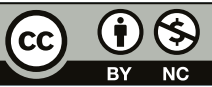

Esta obra está licenciada com uma Licença Creative Commons Atribuição-NãoComercial 4.0 Internacional. 